\title{
O ENSINO DA HISTÓRIA E CULTURA AFRO-BRASILEIRA E INDÍGENA NO CONTEXTO DA GEOGRAFIA ESCOLAR: REFLEXÕES SOBRE A IMPLANTAÇÃO DA LEI 11.645/2008 NA REDE PÚBLICA ESTADUAL DE PERNAMBUCO
}

\author{
Wedmo Teixeira Rosa ${ }^{1}$
}

\begin{abstract}
1 Instituto Federal de Pernambuco (IFPE) - Campus Recife. E-mail: wedmo@recife.ifpe.edu.br. ORCID: http://orcid.org/0000-0003-0435-9523
\end{abstract}

Artigo recebido em 27/02/2021 e aceito em 27/06/2021

\begin{abstract}
RESUMO:
A promulgação da Lei 10.639/2003 e sua posterior ampliação com a Lei 11.645/2008 constituíram-se em instrumentos jurídicos que possibilitaram a sociedade brasileira questionar os conteúdos escolares hegemônicos e exigir ações efetivas que descolonizem os currículos escolares. No entanto, a efetiva implementação dessa legislação na educação básica brasileira e em Pernambuco, em especial, caminha a passos lentos. Este trabalho tem o objetivo de discutir as principais estratégias desenvolvidas pelo Estado de Pernambuco para a efetiva implementação da Lei 11.645/2008 nas escolas da rede estadual de educação e analisar seus desdobramentos no ensino de Geografia. A partir de uma abordagem metodológica qualitativa, realizou-se pesquisas bibliográficas e documentais, além de entrevistas semiestruturadas com sujeitos considerados relevantes (professores, coordenadores pedagógicos e gestores). Constatou-se que apesar do Estado de Pernambuco implantar uma série de ações e estratégias para contribuir com a educação das relações étnico-raciais, ainda existem sérios problemas nesse processo, especialmente em aproximar educadores e gestores da temática e torna-la mais presente no cotidiano escolar. Verificou-se, também, que a Geografia escolar apresenta lacunas nas orientações teórico-metodológicas e práticas de ensino que tratam da temática das relações étnico-raciais.
\end{abstract}

Palavras-chave: Lei 11.645; Relações Étnico-Raciais; Ensino de Geografia; Pernambuco 


\title{
THE TEACHING OF AFRO-BRAZILIAN AND INDIGENOUS HISTORY AND CULTURE IN THE CONTEXT OF SCHOOL GEOGRAPHY: REFLECTIONS ON THE IMPLEMENTATION OF LAW 11,645 / 2008 IN THE STATE PUBLIC NETWORK OF PERNAMBUCO
}

\begin{abstract}
The promulgation of Law 10,639/2003 and its subsequent expansion with Law 11,645/2008 constituted legal instruments that enabled Brazilian society to question the hegemonic school content and demand effective actions that decolonize school curricula. However, the effective implementation of this legislation in Brazilian basic education and in Pernambuco, in particular, is proceeding slowly. This work aims to discuss the main strategies developed by the State of Pernambuco for the effective implementation of Law 11.645/2008 in the schools of the state education network and to analyze its developments in the teaching of Geography. Based on a qualitative methodological approach, bibliographical and documentary research was carried out, in addition to semi-structured interviews with people relevant to the research (teachers, pedagogical coordinators and managers). It was found that despite the State of Pernambuco implementing a series of actions and strategies to contribute to the education of ethnic-racial relations, there are still serious problems in this process, especially in bringing educators and managers to the subject and makes it more present in school life. It was also found that school geography has gaps in the theoretical-methodological guidelines and teaching practices that deal with the theme of ethnic-racial relations.
\end{abstract}

Keywords: Law 11.645; Ethnic-Racial Relations; Geography teaching; Pernambuco.

\section{LA ENSEÑANZA DE LA HISTORIA Y LA CULTURA AFROBRASILEÑA E INDÍGENA EN EL CONTEXTO DE LA GEOGRAFÍA ESCOLAR: REFLEXIONES SOBRE LA IMPLEMENTACIÓN DE LA LEY 11.645 / 2008 EN LA RED PÚBLICA ESTATAL DE PERNAMBUCO}

\begin{abstract}
RESUMEN
La promulgación de la Ley 10.639 / 2003 y su posterior ampliación con la Ley 11.645 / 2008 constituyeron instrumentos legales que permitieron a la sociedad brasileña cuestionar el contenido escolar hegemónico y exigir acciones efectivas que descolonicen los currículos escolares. Sin embargo, la implementación efectiva de esta legislación en la educación básica brasileña y en Pernambuco, en particular, avanza lentamente. Este trabajo tiene como objetivo discutir las principales estrategias desarrolladas por el Estado de Pernambuco para la implementación efectiva de la Ley 11.645 / 2008 en las escuelas de la red educativa estatal y analizar sus desarrollos en la enseñanza de la Geografía. Con base en un enfoque metodológico cualitativo, se llevó a cabo una investigación bibliográfica y documental, además de entrevistas semiestructuradas con gente considerados relevantes (docentes, coordinadores pedagógicos y gestores). Se encontró que a pesar de que el Estado de Pernambuco implementó una serie de acciones y estrategias para contribuir a la educación de las relaciones étnicoraciales, aún persisten serios problemas en este proceso, especialmente en acercar educadores y gestores al tema y hacerlo más presente en la escuela de la vida cotidiana. También se encontró que la geografía escolar presenta vacíos en los lineamientos teórico-metodológicos y prácticas docentes que abordan el tema de las relaciones étnico-raciales.
\end{abstract}

Palabras clave: Ley 11.645; Relaciones Étnico-Raciales; Enseñanza de la Geografía; Pernambuco. 


\section{INTRODUÇÃO}

As questões sobre grupos sociais minoritários e/ou marginalizados ou, ainda, abordagens sobre a diversidade étnico-cultural brasileira não encontram lugar de destaque no currículo escolar, silenciando ou negando as histórias e culturas da população afro-brasileira e indígena. A promulgação da Lei 10.639/2003 e sua posterior ampliação com a Lei 11.645/2008, conferiu obrigatoriedade do ensino da temática história e cultura africana, afro-brasileira e indígena na educação básica, constituindo-se, dessa forma, em um instrumento legal que possibilita a sociedade questionar os conteúdos escolares hegemônicos e exigir ações efetivas que descolonizem os currículos da educação básica e, consequentemente, da educação superior, especialmente dos cursos de licenciaturas.

No entanto, apesar da importância do tema e das discussões que evolvem a Lei 11.645/2008, sua efetiva implementação no contexto da educação básica brasileira, caminha a passos lentos. Em Pernambuco esse cenário não é diferente, pois, como afirma Silva (2012), as ações promovidas pela Secretaria Estadual de Educação para a eficaz inserção dessa temática na rede de ensino do Estado são pontuais e descontínuas, disponibilizando poucos recursos para desenvolver projetos sobre o tema, desconsiderando suas especificidades.

Esse fato se agrava ainda mais quando se trata do componente curricular Geografia, que apresenta lacunas nas orientações metodológicas de práticas de ensino e nos estudos que tratam da temática das relações étnico-raciais na educação básica (MOTA, 2013). É importante ressaltar que a Lei 11.645/2008 atribui, especialmente, aos componentes curriculares de História do Brasil, Literatura e Artes, a inserção da temática história e cultura afro-brasileira e indígena nos seus conteúdos. Mas, ao mesmo tempo, institui que os conteúdos referentes a essa temática devem ser ministrados por todas as disciplinas que fazem parte do currículo escolar, incluindo a Geografia.

A discussão que envolve a educação das relações étnico-raciais coloca em evidência a complexidade do processo de reconhecimento e fortalecimento da cultura e da identidade afrobrasileira e indígena no Brasil, que, apesar dos avanços e conquistas, ainda tem um longo caminho a percorrer. A escola tem papel essencial nesse processo, pois ela é um dos espaços privilegiados para discussão de temas que ajudem os indivíduos a refletirem sobre sua realidade e, dessa maneira, possam agir sobre ela, de forma que todas as configurações de desigualdades sejam superadas e o respeito à diversidade prevaleça numa sociedade que, historicamente, é 
discriminatória nas mais diversas relações sociais. A escola deve ser um espaço de formação do ser humano, ajudando-o a desenvolver o pensamento crítico, reflexivo e a posicionar-se no mundo.

Diante disso, a Geografia escolar precisa contribuir na discussão sobre a educação das relações étnico-raciais, pois, como afirmam Cavalcanti (2013) e Santos (2007), o ensino de Geografia tem um papel importante na formação humana, pois ajuda o indivíduo a conhecer o mundo em que vive, desde a escala local à global, contextualizando-o como um cidadão do mundo, portanto, ajudando-o a posicionar-se no mundo e agir sobre ele. Dessa forma, é fundamental que a temática de história e cultura africana, afro-brasileira e indígena faça parte do conteúdo e de práticas pedagógicas da Geografia escolar, pois as relações étnico-raciais ocorrem espacialmente, o que permite evidenciar os espaços de lutas, resistências, desigualdades e da diversidade cultural brasileira.

Nesse contexto, o objetivo deste trabalho é discutir as principais ações e estratégias desenvolvidas pelo Estado de Pernambuco para a efetiva implementação da Lei 11.645/2008 nas escolas da rede estadual de educação e analisar seus desdobramentos no ensino de Geografia na Região Metropolitana do Recife (RMR).

Considerando as proposições discutidas acima, a abordagem metodológica deste trabalho tem caráter qualitativo, já que esse tipo de abordagem busca compreender o objeto de estudo dentro de seu contexto e a partir de interpretações de informações não numéricas, reunindo procedimentos, instrumentos e técnicas de pesquisa variadas (DENZIN; LINCOLN, 2006). Em relação ao conjunto de procedimentos metodológicos, diversos instrumentos e técnicas de pesquisas qualitativas foram utilizados, destacando-se a revisão bibliográfica, pesquisa documental e entrevistas.

Inicialmente foi realizado um aprofundamento e ampliação das leituras que teve por finalidade conhecer as diferentes concepções científicas acerca do objeto de estudo, fazendo-se consultas a livros, teses, dissertações, artigos científicos, etc., contribuindo, dessa forma, para aproximação e aprofundamento teórico-conceitual do tema proposto.

Outro procedimento importante foi a pesquisa e análise documental. Nesse intento foi realizada uma busca por documentos, diretrizes, leis, normativas, pareceres jurídicos e planos de ações relacionados a implantação da Lei 11.645/2008 em sites do Ministério da Educação 
(MEC) e da Secretaria Estadual de Educação de Pernambuco (SEE) para conhecer e analisar os aspectos legais que permeiam as ações, especialmente do Estado de Pernambuco, para o desenvolvimento de uma educação das relações étnico-raciais.

Além da revisão bibliográfica e pesquisa documental, foram desenvolvidas entrevistas semiestruturadas com agentes considerados relevantes para esclarecer e aprofundar algumas questões pertinentes ao problema central deste trabalho: 8 (oito) gestores e coordenadores pedagógicos e 19 (dezenove) docentes do componente curricular Geografia da rede estadual de ensino que lecionam em municípios da RMR. Importante ressaltar que, diante do quadro de pandemia da Covid-19 que o país e o mundo enfrentam atualmente, as entrevistas foram realizadas de forma remota e em alguns casos foram aplicados questionários online (Google Forms), quando as entrevistas não puderam ser realizadas. Neste trabalho, os nomes dos colaboradores entrevistados são fictícios para preservar sua identidade.

O tratamento e análise dos dados e informações - levantados a partir da pesquisa documental e entrevistas semiestruturadas (ou questionários online) - foi realizado a partir da Análise de Conteúdo (BARDIN, 2011), buscando-se evidenciar as acepções dos núcleos de sentido e significação das informações por meio da análise temática.

\section{MOVIMENTOS SOCIAIS, LEI 11.645/2008 E DESCOLONIZAÇÃO DO CURRÍCULO: BREVE DISCUSSÃO}

Em 9 de janeiro de 2003 foi promulgada a Lei Federal 10.639, que alterou os artigos 26-A e 79-B da Lei 9.394/1996 - Lei de Diretrizes e Bases da Educação Nacional (LDB) e tornou obrigatório o ensino de história e cultura afro-brasileira em toda a rede de ensino da educação básica do Brasil. Depois de 5 (cinco) anos foi promulgada a Lei Federal 11.645 de 11 de março de 2008, que ampliou a Lei 10.639/2003 ao acrescentar a obrigatoriedade, também, do ensino de história e cultura indígena nas escolas de educação básica. Outros importantes instrumentos legais nesse sentido são o Parecer CNE/CP 3/2004 e a Resolução CNE/CP 1/2004 que dispõem sobre as Diretrizes Curriculares Nacionais para a Educação das Relações ÉtnicoRaciais e para o Ensino de História e Cultura Afro-Brasileira e Africana (BRASIL, 2004).

Segundo Santos (2010) a Lei 10.639/2003 é uma conquista do Movimento Negro, tornando-se um instrumento fundamental de luta pela promoção de uma educação para a 
igualdade racial, abrindo possibilidades de discussões da necessidade de mudanças nos conteúdos ensinados em todos os níveis da educação.

O movimento social negro no Brasil tem uma longa história de resistências, lutas e conquistas, apesar de assumir posturas políticas diversas e apresentar uma descontinuidade temporal devido ao contexto histórico ao qual estava inserido (DOMINGUES, 2007), o que é comum em qualquer movimento social. No entanto, a partir do final da década de 1970 o movimento social negro organizado se mobiliza de forma mais crítica e articulada em prol da promoção de uma justiça racial, fazendo parte de sua agenda de luta política uma variedade de eixos, como a valorização de símbolos associados a cultura negra, política de identidade negra, ação política e jurídica de criminalização do racismo, inclusão do ensino de história e cultura afro-brasileira na educação básica, entre outros.

Destaca-se aqui o último eixo de luta listado acima, pois ele está totalmente atrelado aos propósitos deste trabalho. A obrigatoriedade de inclusão nos currículos escolares do ensino de história e cultura afro-brasileira é uma reivindicação antiga do movimento negro que se consolida em 2003 com a promulgação da Lei 10.639.

Além disso, os processos e debates para implementação dessa Lei abriram espaço para a discussão e/ou fortalecimento de outras pautas, como da inserção obrigatória do ensino de história e cultura indígena no currículo escolar, o que foi conseguido com a promulgação da Lei 11.645/2008. Esta Lei complementa a anterior, acrescentando a temática história e cultura indígena, como já citado anteriormente.

Os povos indígenas no Brasil sempre foram marginalizados pelo Estado e pela sociedade. De acordo com Silva (2016), só depois da promulgação da Constituição Federal do Brasil, em 1988, que esses povos começaram a ter um reconhecimento de direitos que mudariam sua situação no quadro social de nosso país. A participação em movimentos sociais, que já ocorriam antes da Constituição de 1988, mobilizou diversos povos indígenas e contribuíram na luta pelo reconhecimento de seus direitos e no fortalecimento de uma identidade indígena.

No âmbito da educação, por exemplo, os povos indígenas conquistaram o direito de ter uma educação diferenciada dentro de suas aldeias, como prever a LDB. Outra conquista importante dentro desse contexto é a Lei $11.645 / 2008$, que promove e valoriza a temática 
história e cultura indígena no currículo escolar de toda a educação básica brasileira. Para Vieira e Rosa (2019, p. 220):

A lei, então, efetiva, ao menos na teoria, as discussões que foram se estabelecendo durante o último quartel do século $\mathrm{XX}$, bem como as próprias ações dos povos indígenas, mostrando que não estão extintos, como muitos pensam, mas sim estão atuando incessantemente no contexto social e são, por vezes, invisibilizados.

A promulgação das Leis 10.639/2003 e 11.645/2008 se constitui na formalização de uma reivindicação dos movimentos sociais negros e indígenas no campo da educação, o que demonstra que o ordenamento jurídico sobre desigualdade étnico-racial no Brasil só é implementado a partir de reivindicações de direitos e de árduas lutas promovidas pela sociedade organizada. Essas disputas estabeleceram um importante marco histórico na educação brasileira, pois abriu grandes possibilidades para discussões de questões que envolvem as relações étnico-raciais, o que perpassa pela descolonização do currículo e do saber.

O contexto do mundo atual traz indagações e mudanças relevantes sobre a produção do conhecimento e, consequentemente, possibilitando uma maior diversidade epistemológica que fundamenta essa produção. Esse processo reverbera sobre as práticas pedagógicas e sobre o conteúdo escolar, questionando interpretações e conceitos clássicos da teoria educacional. Nesse sentido, o currículo escolar precisa mudar para atender essa demanda do campo educacional e se aproximar cada vez mais da realidade social na qual os sujeitos do processo educativo estão inseridos.

De acordo com Santos (2006 apud GOMES, 2012) a teoria educacional e o campo do currículo apresentam duas vertentes principais: a) interna, que questiona o caráter monolítico do cânone epistemológico; e b) a externa, que se concentra nas relações entre a ciência e outros conhecimentos, questionando a exclusividade epistemológica da ciência. Gomes (2012, p. 99), contribui com essa discussão afirmando que

[...] na teoria educacional e na prática do currículo, esses dois conjuntos de
epistemologias são produzidos por um movimento dinâmico: as reflexões internas à
ciência e as questões colocadas pelos sujeitos sociais organizados em movimentos
sociais e ações coletivas ao campo educacional. Quanto mais se amplia o direito à
educação, quanto mais se universaliza a educação básica e se democratiza o acesso ao
ensino superior, mais entram para o espaço escolar sujeitos antes invisibilizados ou
desconsiderados como sujeitos de conhecimento. Eles chegam com os seus
conhecimentos, demandas políticas, valores, corporeidade, condições de vida,
sofrimentos e vitórias. Questionam nossos currículos colonizados e colonizadores e
exigem propostas emancipatórias.

A Lei 11.645/2008, no contexto dessa discussão, se constitui em um instrumento legal que possibilita questionar os currículos escolares, exigindo ações efetivas que mudem práticas 
pedagógicas e descolonizem os currículos da educação básica e superior no que se refere as relações étnico-raciais no Brasil. O currículo escolar brasileiro é rígido e conteudista, elaborado a partir de concepções eurocêntricas, o que implica maneiras de ver e ler o mundo e que se refletem em modos de ser e agir sobre ele. Dessa maneira, essa concepção de currículo precisa mudar.

Segundo Santos (2010, p. 142), a construção do currículo pode ser entendida a partir de disputas de poder entre diversos agentes sobre como um conjunto de saberes devem ser produzidos, discutidos e difundidos no ambiente escolar, devendo ser considerado como um "fluxo", mais do que uma simples listagem de conteúdo. Compreender o currículo como um "fluxo" que está em constante disputa é fundamental para descolonizá-lo e mudar sua concepção rígida e centrada em uma cultura hegemônica que enfatiza seus saberes e silencia outros considerados marginalizados.

A obrigatoriedade do ensino de história e cultura afro-brasileira e indígena na educação básica abre caminhos para tornar visíveis grupos sociais historicamente marginalizados, para discutir a questão racial e étnica no Brasil, valorizar as lutas e conquistas promovidas pelos movimentos sociais, reconhecer a importância histórica e cultural dos povos negros e indígenas para a formação da sociedade brasileira, entre tantas outras pautas importantes.

Quando se discute a descolonização do currículo, apregoa-se a importância de concebê-lo como um "fluxo" que deve atender as diversas demandas da sociedade, sendo que sua revisão e (re)construção deve ser constante e preocupada com o diálogo entre o conhecimento, a escola e a realidade social na qual os sujeitos estão inseridos, valorizando suas histórias, culturas, lutas, resistências, conquistas e saberes, o que envolve, ainda, a reflexão e reelaboração de práticas pedagógicas que possam se articular com as demandas desse currículo descolonizado. Esse processo não é uma tarefa fácil, mas é necessário e urgente, devendo envolver não apenas as escolas, mas também as universidades, movimentos sociais, políticas públicas e toda a sociedade. 


\section{AÇões E ESTRATÉGIAS PARA PROMOÇÃO DA EDUCAÇÃo DAS RELAÇÕES ÉTNICO-RACIAIS NA REDE PÚBLICA ESTADUAL DE PERNAMBUCO}

O Estado de Pernambuco, através da Secretaria Estadual de Educação (SEE), construiu aportes legais e estratégias que dão base para implantação da Lei 11.645/2008, como:

- a Instrução Normativa $n^{\circ}$ 04/2011 da SEE/PE, que orienta procedimentos para à inclusão da temática "história e cultura afro-brasileira e indígena" no currículo oficial das escolas integrantes do sistema estadual de ensino (PERNAMBUCO, 2011, p. 13);

- a inclusão de diretrizes e estratégias que abordam a temática da educação das relações étnico-raciais no Plano Estadual de Educação, Lei no 15.533 , de 23 de junho de 2015 (PERNAMBUCO, 2015, p. 3-9), e no Decreto nº 48.477/2019, que institui o Regimento Escolar da Rede Estadual de Ensino do Estado de Pernambuco (PERNAMBUCO, 2019, p. 4-12);

- a criação do Núcleo de Educação das Relações Étnico-Raciais (NERER) em 2015 para trabalhar com a elaboração, coordenação, monitoramento, execução e assessoria com as ações relativas à temática, vinculado à Gerência de Políticas Educacionais em Educação Inclusiva, Direitos Humanos e Cidadania (GEIDH) (SEE, 2021);

- a promoção de formação continuada para docentes da rede estadual de ensino sobre a temática história e cultura africana, afro-brasileira e indígena e realização de simpósios sobre educação das relações étnico-raciais (SEE, 2021);

- elaboração do Plano de Institucionalização do Ensino da História e Cultura AfroBrasileira e Indígena na Rede Estadual de Educação de Pernambuco ${ }^{1}$ em 2016;

A Instrução Normativa 04/2011 da SEE/PE é o principal instrumento jurídico, no contexto do Estado de Pernambuco, que orienta procedimentos para inclusão da temática história e cultura afro-brasileira e indígena no currículo oficial das escolas do sistema estadual de ensino. Outros documentos jurídicos fundamentais são: o Plano Estadual de Educação 2015-

\footnotetext{
${ }^{1}$ Informado por um dos gestores vinculados a SEE. Não encontramos esse documento nos canais de internet da SEE. Porém a Gerência Regional de Educação (GRE) Metropolitana Norte forneceu dois Planos Regionais que é vinculado ao Plano Estadual.
} 
2025, que inclui diretrizes e estratégias que, entre outros pontos importantes, visam garantir a efetiva implementação da Lei 11.645/2008 e o cumprimento do Plano Nacional de Implementação das Diretrizes Curriculares Nacionais para a Educação das Relações ÉtnicoRaciais e para o Ensino de História e Cultura Afro-Brasileira, Africana e Indígena; e o Regimento Escolar da Rede Estadual de Ensino do Estado de Pernambuco, que reforça, em seu Art. 12, a obrigatoriedade do ensino da história e cultura afro-brasileira e indígena nas unidades escolares, sugerindo, inclusive, alguns conteúdos para serem discutidos nos diversos componentes curriculares.

A Instrução Normativa 04/2011 da SEE/PE se alinha com os objetivos da Lei 11.645/2008 e outros instrumentos legais em âmbito federal que tratam da temática da educação das relações étnico-raciais, como o Parecer CNE/CP nº 03/2004 e a Resolução CNE/CP n ${ }^{\circ}$ 01/2004, que institui diretrizes curriculares nacionais para a educação das relações étnicoraciais e para o ensino de história e cultura afro-brasileira e africana.

Uma das questões que chama a atenção nessa normativa, está em seu Art. $3^{\circ}$ :

O Sistema Estadual de Ensino e as entidades mantenedoras para assegurar a Educação das Relações Étnico-Raciais e o estudo de História e Cultura Afro-Brasileira e Indígena, deverão:

I - prover as escolas de condições materiais e financeiras, assim como de acervo documental referente à legislação educacional específica, material bibliográfico e didático necessários;

II - garantir formação continuada para professores, com vistas à efetivação de práticas pedagógicas, cujo foco seja a Educação das Relações Étnico-Raciais e o estudo de História e Cultura Afro-Brasileira e Indígena. (PERNAMBUCO, 2011, p. 13).

Como pode ser observado na citação acima, as condições materiais e financeiras e a capacitação de docentes para o desenvolvimento de práticas pedagógicas voltadas a educação das relações étnico-raciais devem ser asseguradas pelo sistema estatual de ensino e de suas entidades mantenedoras. Porém, um relato recorrente dos professores que lecionam o componente curricular Geografia no ensino médio da rede pública estadual (sujeitos desta pesquisa) é a falta de materiais didáticos, bibliográficos e de apoio e recursos financeiros para o desenvolvimento de projetos que contemplem a educação das relações étnico-raciais.

Tomando-se como referência as respostas dos docentes entrevistados, grande parte das escolas públicas estaduais de ensino médio localizadas na RMR não oferecem uma base material de apoio para o desenvolvimento de ações e práticas pedagógicas relacionadas a educação das relações étnico-raciais, pois as bibliotecas, quando existem, carecem de livros, 
documentos, diretrizes que abordam o assunto; faltam equipamentos como Datashow, computadores com acesso à internet, impressoras, máquina de xérox, televisores; aparelhos de som; e até mesmo materiais simples como cartolina, papel, piloto de quadro, entre outros, como destaca uma professora: "na escola que eu trabalho não tem computador pra gente [professor/a], o Datashow não funciona, eu peço uma xérox e não tem papel ou tá sem toner [...], até o pincel eu compro. É desanimador, sabe? A gente quer até fazer um trabalho desses, mas não me sinto estimulada" (Professora Maria) ${ }^{2}$.

Vale ressaltar que tiveram professores que relataram exatamente o contrário: "a escola fornece tudo. Se a gente quiser usar Datashow tem, se quiser imprimir também tem, a gente tem [máquina de] xérox, então podemos xerocar à vontade. Todo material que eu uso com os meninos: cartolina, piloto, tinta, pincel; todo material que eu quiser usar a escola tem" $(\text { Professora Rita })^{3}$. Mas essa não é uma realidade observada em grande parte das escolas de ensino médio da rede estadual de educação de Pernambuco, com exceção, em grande parte, das Escolas de Referências em Ensino Médio e, principalmente, das Escolas Técnicas Estaduais.

Sobre a formação continuada, percebeu-se que existe um esforço da SEE para garantir capacitação aos professores da rede estadual pública de ensino sobre a educação das relações étnico-raciais. Os professores e gestores entrevistados destacaram dois eventos nesse sentido: os simpósios temáticos e os ciclos de formação.

Os simpósios temáticos são uma referência ao "Simpósio Estadual para Educação das Relações Étnico-Raciais" que ocorre anualmente desde 2015 e é organizado pelo NERER/SEE. Este evento vem se tornando umas das principais ações institucionais da SEE para discussão, trocas de experiências e divulgação de estratégias para implementação da temática história e cultura africana, afro-brasileira e indígena nas escolas da rede estadual de ensino de Pernambuco. Talvez, por isso, tenha uma demanda grande para participação nesse evento:

No simpósio a gente tem que limitar a participação porque demanda custos de hospedagem e transporte. Faz-se distribuição de vagas para as regionais [GRE] em número igualitário. Um critério que a gente usa é trazer um professor que tenha tido uma atividade exitosa, os outros são escolhidos pelos critérios das Regionais. Como é um simpósio, a gente chama também pessoas que não são da educação: militantes de movimentos sociais, pesquisadores, etc. (Gestor José) ${ }^{4}$.

\footnotetext{
${ }^{2}$ Formada em Licenciatura em História, 48 anos. Leciona História, Geografia e Sociologia.

${ }^{3}$ Formada em Licenciatura em Geografia. 39 anos. Leciona Geografia e Artes.

${ }^{4}$ Formado em Licenciatura em História e Letras. Leciona na rede estadual de ensino de Pernambuco há 26 anos e é militante de movimentos sociais.
} 
O simpósio ocorre em municípios diferentes, como Recife, Itamaracá, Gravatá, e participam representantes indicados pelas Gerências Regionais de Educação (GRE). No ano de 2020, a VI edição desse evento aconteceu em dezembro e foi realizada de forma virtual por causa da pandemia do Coronavirus (COVID-19). Seria interessante que esse formato possa ser usado para transmissão das discussões presenciais (quando for possível serem realizadas) promovidas no simpósio, fazendo chegar a um número maior de educadores. Além do mais, esse formato permite que a gravação do evento seja disponibilizada em plataformas virtuais que podem ser acessadas pela internet, possibilitando que professores, gestores e estudantes assistam as discussões em outros momentos.

Quanto aos ciclos de formação, um dos gestores vinculado a SEE afirmou que são oferecidos cursos de capacitação, com periodicidade anual, para professores e gestores que trabalham em escolas estaduais localizadas na $\mathrm{RMR}^{5}$, abordando várias temáticas: avaliação, tecnologias na educação, relações de gênero, relações étnico-raciais, etc. Esses cursos pretendem contribuir com a formação continuada dos docentes. As Gerências Regionais Metropolitana Norte e Recife Sul informaram que convidam dois ou três representantes das escolas do sistema de ensino estadual que estão em sua área de atuação para serem multiplicadores nas suas instituições de ensino.

As formações de professores são pontuais para todos os professores. E como eu disse a você, o tema já vem pronto e toda a dinâmica da metodologia é passada para o professor que participou da formação para ele ser um multiplicador aqui na escola. Aí ele chega com as ideias e a gente agenda [...], a gente faz o agendamento geralmente na primeira reunião de fevereiro de todos os projetos a serem trabalhados durante o ano letivo. Aí, com relação às questões étnico-raciais elas são iniciadas em novembro na semana da Consciência Negra. (Coordenadora Laura) ${ }^{6}$.

Os cursos de formação continuada são importantes no contexto da educação das relações étnico-raciais, pois essa é uma temática que historicamente foi invisibilizada na formação inicial do professor, ocorrendo mudanças efetivas nesse sentido apenas a partir de 2015, com a Resolução CNE/CP nº 02, de 1 de julho de 2015, que define as Diretrizes Curriculares Nacionais para a formação inicial em nível superior (cursos de licenciatura, cursos de formação pedagógica para graduados e cursos de segunda licenciatura) e para a formação continuada.

\footnotetext{
${ }^{5}$ A pesquisa desenvolvida se limitou as Gerências Regionais de Educação Metropolitana Norte e Recife Sul. Por isso não foi possível constatar a realização e periodicidade de cursos de formação continuada em outras gerências regionais.

${ }^{6}$ Formada em Licenciatura em Geografia e Pedagogia, 35 anos. Coordenadora pedagógica.
} 
Discutir ações, estratégias, desafios, importância, etc. da Lei 11.645/2008 no contexto da formação inicial e continuada do professor é fundamental para sua efetiva implementação. Para além do cumprimento da Lei, o mais importante é formar professores que contribuam com uma educação antirracista e sejam profissionais e didadãos preocupados no combate contra o racismo e diminuição das desigualdades étnico-raciais. No entanto, a questão da formação docente ainda é um problema no que diz respeito a educação das relações étnico-raciais:

Podemos afirmar, sem maiores temores, que um dos principais problemas que atingem o enfoque da história africana nas salas de aula é a formação "inadequada" dos professores que atuam nos Ensinos Fundamental e Médio. Em algumas conversas que mantive com docentes de escolas públicas e privadas constatei que, muitos deles, não abordavam o assunto em sala justamente por não terem sido apresentados à temática anteriormente. O acesso não orientado aos estudos publicados sobre a História da África (nem sempre de boa qualidade) e a insegurança para montar suas aulas eram consequências diretas dessa falha. Outros professores, diante da impossibilidade de ministrar todos os tópicos dos programas, consideravam o tema de menor importância, deixando de lado os capítulos sobre a África presentes nos livros didáticos (quando estes existiam é claro). Também não podemos deixar de mencionar as reconfortantes exceções, com algumas excelentes iniciativas individuais. (OLIVA, 2006, p. 191).

O fragmento acima trata da história africana, mas pode-se ampliar essa leitura, também, para a história e cultura indígena, ainda mais porque os discursos e imagens sobre os povos indígenas são ainda mais distorcidos (WITTMAN, 2015). Pode-se associar a citação acima diretamente com uma questão recorrente entre os professores: como ensinar o que não se aprendeu? O aprendizado é contínuo e deve ser renovado a partir da reflexão crítica sobre a prática. Daí a importância da formação continuada, pois é necessário que o professor encontre as condições para desenvolver esse aprendizado. Nesse sentido, tanto os cursos de formação inicial quanto os de formação continuada precisam formar professores preparados para atender as demandas da sociedade no que se refere ao processo educativo, o que requer políticas públicas e investimentos direcionados para a educação, pois apenas a formação não adianta, a escola precisa ter as condições necessárias para o desenvolvimento de práticas pedagógicas diversas.

[...] O que é discutido lá nos cursos de formação é uma coisa totalmente fora do contexto escolar. Uma coisa você fala teoricamente como você poderia desenvolver trabalhos, outra coisa é quando chega na escola e você não tem estrutura nenhuma para colocar isso em prática: não tem computador, não tem datashow, não tem som para usar músicas, essas coisas, nada! Aí você tem que improvisar. Uma coisa é você falar, outra é você fazer aquilo. Aí muitas vezes a gente até prefere não ir nesses cursos, não participar, porque não há uma relação com a escola. (Professora Eliza) ${ }^{7}$.

\footnotetext{
${ }^{7}$ Formada em Licenciatura em Geografia, 46 anos. Leciona Geografia.
} 
Promover a formação continuada para professores sobre a educação das relações étnico-raciais é fundamental para ajudar na efetivação de práticas pedagógicas que abordem a temática de história e cultura afro-brasileira e indígena, mas, ao mesmo tempo, é preciso fornecer as condições mínimas de trabalho para motivar a comunidade escolar na concretização dessas práticas.

Sobre a referência ao Plano de Institucionalização do Ensino da História e Cultura Afro-Brasileira e Indígena na Rede Estadual de Educação de Pernambuco, não encontramos um documento específico que tratasse do assunto. A GRE Metropolitana Norte dispõe de um documento intitulado "Plano de ação regional para a educação das relações étnico-raciais e para o ensino de história e cultura afro-brasileira e africana" que orienta o desenvolvimento de ações para implementar e disseminar a Lei 10.639/2003, promover formação continuada, construir propostas pedagógicas e incentivar pesquisas sobre a temática (SECRETARIA ESTADUAL DE EDUCAÇÃO, 2016).

É importante ressaltar que nesse plano existe um cronograma de atividades previstas para serem realizadas no período de 1 (um) ano, onde se destacam: o acompanhamento do cumprimento da legislação nas unidades escolares; reuniões frequentes com gestores e docentes; e a formação continuada. Outro ponto de destaque é que a temática história e cultura indígena não aparece de forma efetiva na proposta, enfatizando-se a temática história e cultura afro-brasileira e africana nos objetivos específicos do documento, com algumas menções a Lei $11.645 / 2008$.

Apesar do desenvolvimento dessas diversas estratégias discutidas anteriormente, a implementação da temática história e cultura africana, afro-brasileira e indígena nas escolas de ensino médio do sistema estadual de educação na RMR não se dá de forma efetiva, apresentando diversos problemas e desafios na execução de projetos e ações que vão desde a formação continuada até o cotidiano da sala de aula, especialmente quando se trata da inserção dessa discussão no programa de ensino dos componentes curriculares em geral. No componente curricular Geografia, por exemplo, a temática das relações étnico-raciais é bastante pontual e deficitária. 


\section{DESDOBRAMENTO DA EDUCAÇÃO DAS RELAÇÕES ÉTNICO-RACIAIS NO ENSINO DE GEOGRAFIA: A REGIÃO METROPOLITANA DO RECIFE EM CONTEXTO}

Ao se analisar os Parâmetros para a Educação Básica do Estado de Pernambuco Geografia Ensino Médio (PERNAMBUCO, 2013), percebe-se que a temática étnico-racial só aparece no Eixo Temático Dinâmica Populacional, destacando a Expectativa de Aprendizagem "compreender a formação sociocultural e a diversidade étnico-racial da população brasileira", para ser trabalhada nos $1^{\circ}$ e $2^{\circ}$ Anos. As palavras indígena e afro-brasileira sequer são mencionadas no documento.

No documento Reorganização Curricular - Ensino Médio, elaborado em 2020, não houve muitas alterações quanto as orientações de trabalho com a temática história e cultura afro-brasileira e indígena no componente curricular Geografia. A temática étnico-racial aparece de forma clara no Eixo/Campo Espaço Urbano e Espaço Rural no conteúdo de Formação do Território Brasileiro e da Sociedade Brasileira, tendo como Expectativa de Aprendizagem Prioritária "compreender a formação sociocultural e a diversidade étnico racial da população brasileira", com indicação de trabalho para o $3^{\circ}$ Ano e, também, a temática é apontada para o $2^{\circ}$ Ano no Eixo/Campo Dinâmica Populacional no conteúdo Características da População do Mundo e do Brasil, tendo como Expectativa de Aprendizagem Complementar "compreender a formação sociocultural e a diversidade étnico-racial da população brasileira" (PERNAMBUCO, 2020). Da mesma forma que o documento anterior, as palavras indígena e afro-brasileira não são mencionadas no texto.

Esses documentos sevem de referências para o trabalho pedagógico nos diversos componentes curriculares que compõem o currículo escolar. Isso quer dizer que a unidade escolar deve construir o seu currículo com base nessas orientações, mas que, também, pode ser enriquecido a partir de discussões na própria escola.

Os professores de Geografia do sistema estadual de ensino de Pernambuco diante dos documentos orientadores apresentados acima tem um desafio enorme para implantar a temática história e cultura africana, afro-brasileira e indígena nos programas de ensino desse componente curricular, tendo que inseri-la nas propostas curriculares construídas na escola e, assim, contribuir com a educação das relações étnico-raciais. 
Santos (2010) sugere algumas alternativas de como trabalhar essa temática na Geografia: a geografia africana por meio de novas perspectivas da história da África, os espaços e suas relações; As relações cotidianas entre "raças" e suas localizações espaciais do centro à periferia; A existência e resistência quilombola; Toponímia: a nomeação de lugares a partir de heranças históricas da cultura negra que foram ocultadas. Além disso, como esses temas são amplos, podem ser trabalhados de diversas maneiras: filmes, projetos, músicas, entre outros. Essas são propostas de trabalho da temática no âmbito da Geografia, que devem servir de inspiração para que os professores desta área do conhecimento introduzam no seu programa de ensino conteúdos que possibilitem a realização de práticas pedagógicas voltadas para a educação das relações étnico-raciais

Um dado importante no contexto deste trabalho se revelou quando foi inquirido aos professores se eles conhecem ou já ouviram falar da Lei 11.645/2008 ou da Lei 10639/2003: $42,1 \%$ disseram que conhecem; 36,8\% afirmaram que já ouviram falar; e 21,1\% revelaram que não conhecem. Esses dados mostram que pouco mais de $3 / 4$ dos docentes entrevistados "conhecem "ou já "ouviram falar" da legislação que trata da obrigatoriedade do ensino de história e cultura afro-brasileira e indígena na educação básica. Esse é um passo relevante, pois conhecer as Leis é fundamental para sua efetiva implementação. No entanto, ainda é expressivo o número de professores que não conhecem essa legislação, especialmente por que trabalham na educação básica. Além disso, a variável “já ouvi falar" carrega um caráter subjetivo, o que pode aumentar para mais da metade o quantitativo de professores que não conhecem a Lei $11.645 / 2008$.

Outra informação significativa para este estudo é sobre as principais formas de promoção e/ou incentivo de discussão sobre a temática história e cultura afro-brasileira e indígena na unidade escolar. Entre os professores de Geografia entrevistados, 68,4\% afirmaram que discutem a temática a partir da realização de eventos promovidos na unidade escolar; $21,1 \%$ aborda o assunto nas suas aulas durante o ano letivo; e 1,1\% não promove ou participa de ações para desenvolvimento da temática na sua prática docente.

Como pode ser observado, a realização de eventos, como feiras culturais, projetos educativos e palestras, são o principal gatilho para abordagem da temática que envolve a educação das relações étnico-raciais. No entanto, deve-se chamar a atenção que grande parte desses eventos ocorrem em datas comemorativas, como no dia ou semana da Consciência 
Negra, restringindo a discussão da temática a determinados dias. A fala de um professor é reveladora nesse sentido: “[...] com relação à questão étnico-raciais, trabalhamos em novembro, na semana da Consciência Negra. Os professores de Geografia, todos os professores, principalmente os de humanas, trabalham na sala de aula e fazemos a culminância, que é muito bem feita aqui na escola" (Professor Pedro) ${ }^{8}$.

Numa análise geral sobre as ações e abordagens da temática história e cultura afrobrasileira e indígena feitas pelos professores de Geografia de unidades escolares localizadas na RMR, percebe-se que seu desenvolvimento ocorre de forma desigual e descontínua. O sucesso de projetos sobre o tema e/ou promoção efetiva da discussão na sala de aula ocorre a partir de iniciativas individuais, muitas vezes porque são realizadas por professores engajados em movimentos sociais ou que realmente se preocupam com questões que envolvem a educação das relações étnico-raciais.

A temática história e cultura africana, afro-brasileira e indígena precisa ser institucionalizada no currículo e no cotidiano escolar para não ficar restrita a iniciativas individuais e dias comemorativos. Nesse sentido, as diversas áreas do conhecimento que fazem parte da educação básica, especialmente aquelas das ciências humanas e sociais, devem assumir um papel de protagonistas nesse processo, contribuindo de forma efetiva para uma reflexão sobre o currículo e práticas de ensino que, de fato, descolonizem o saber e atendam as diversas demanda da sociedade na busca por uma formação mais humana, crítica e reflexiva. Nesse contexto, o ensino de Geografia, tem papel fundamental, pois essa é uma área do conhecimento que estuda a relação entre sociedade e espaço, ajudando o indivíduo a compreender melhor o mundo em que vive e a se posicionar e agir sobre ele.

É por isto que o sentido do aprender e ensinar a Geografia é se posicionar no mundo. E, precisamos assumir uma dupla acepção do que chamamos "se posicionar no mundo": (i) conhecer sua posição no mundo, e para isto o indivíduo precisa conhecer o mundo; (ii) tomar posição neste mundo, que significa se colocar politicamente no processo de construção e reconstrução desse mundo. Se posicionar no mundo é, portanto, conhecer a sua posição no mundo e tomar posição neste mundo, agir. Saber Geografia é saber onde você está, conhecer o mundo, mas isto serve fundamentalmente para você agir sobre esse mundo no processo de reconstrução da sociedade: se apresentar para participar (SANTOS, 2010, p. 142-143)

Essa concepção do ensino de Geografia está diretamente relacionada com uma educação crítica, reflexiva e participativa, que valorize e reconheça os contextos sociais nos

\footnotetext{
${ }^{8}$ Formado em Licenciatura em Geografia, 33 anos. Leciona Geografia e Química.
} 
quais os sujeitos envolvidos no processo educativo estão inseridos. Dessa forma, o ensino de Geografia deve contribuir com a implantação efetiva da Lei 11,645/2008 na educação básica, especialmente no que diz respeito às desigualdades raciais e étnicas; o ensino sobre a África; vivências espaciais dos diversos grupos étnico-raciais; as discussões sobre os territórios de lutas e resistências negra e indígena no Brasil; diversidade étnico-racial; identidade territorial; entre tantos outros temas que possibilitem a sociedade brasileira conhecer melhor o seu território e seu povo, valorizando e reconhecendo a importância social, econômica, política e cultural da história e cultura afro-brasileira e indígena para a formação social e territorial do Brasil.

Para tanto, é preciso romper com algumas tendências hegemônicas do ensino de Geografia que, assim como outras áreas do conhecimento, privilegia o saber ocidental eurocêntrico. Um exemplo disso perpassa pela relação direta que é feita entre a ideia de raça e o espaço, forjando identidades territoriais e geoculturais do mundo, pois, por exemplo, geralmente quando se fala em África, uma associação direta é feita com os negros; o mesmo ocorre com os brancos, índios e amarelos, que são, respectivamente, associados a uma origem europeia, americana e asiática (QUIJANO, 2007). Esse é apenas um exemplo das construções artificiais e distorcidas da realidade, que estão fundamentadas numa História e Geografia universais baseadas no eurocentrismo. Essas concepções são veiculadas e difundidas (não só pela Geografia e História) no ambiente escolar como conhecimento hegemônico, reproduzindo e naturalizando visões de mundo ultrapassadas e estereotipadas da realidade.

Com a promulgação da Lei 11.945/2008, algumas mudanças já ocorreram nesse sentido, mas elas ainda não poucas em relação ao que precisa ser feito. Um exemplo disso se expressa nas mudanças engendradas nos livros didáticos de Geografia nos últimos anos, que foram realizadas para atender uma exigência da norma jurídica citada, onde incluíram e/ou ampliaram em seus conteúdos as discussões que envolvem o continente africano e a história e cultura afro-brasileira e indígena, mas sem grandes aprofundamentos de debates políticos e filosóficos. Segundo Mota (2013, p. 111), os livros didáticos de Geografia do ensino básico abordam a importância das matrizes indígenas e africanas para a construção da identidade brasileira, mas ainda de forma folclórica e/ou sem grande destaque sobre sua participação na formação socioeconômica do Brasil.

As abordagens sobre a temática da história e cultura afro-brasileira e indígena precisam levar em conta sua dimensão política, ideológica e filosófica, e não apenas a dimensão 
economicista como hegemonicamente é feito, para tratar de maneira crítica e reflexiva do real sentido das relações raciais e étnica existente em nosso país e ultrapassá-las, principalmente no que diz respeito às desigualdades étnico-raciais.

\section{CONSIDERAÇÕES FINAIS}

Uma das principais problemáticas, de modo geral, para se tratar a temática das relações étnico-raciais no ensino está relacionado à superação do saber colonizado e colonizador, que perpetuam e (re)produzem imaginários que inferiorizam povos indígenas e afro-brasileiros, e caminhar na direção de visões de mundo e saberes mais críticos, buscando problematizar os mitos de identidades generalizantes, que sobretudo, funcionam como mecanismos que invisibilizam e marginalizam determinados grupos sociais. Desta maneira, a educação das relações étnico-raciais objetiva o fortalecimento de identidades e de direitos, através da promoção de ações de combate ao racismo e às discriminações, pautando-se nos princípios da consciência política da diversidade histórica e cultural da população brasileira.

No sistema estadual de ensino de Pernambuco, mais especificamente em escolas do ensino médio localizadas na Região Metropolitana do Recife, verifica-se a criação de diversas estratégias para colaborar com a implantação efetiva do ensino de história e cultura africana, afro-brasileira e indígena, mas sem grande avanço. Foram concebidos, por exemplo, instrumentos jurídicos, secretarias especiais, cursos de formação continuada e eventos específicos para promover uma educação das relações étnico-raciais, contudo, percebe-se a falta de políticas públicas educacionais efetivas e uma descontinuidade de ações, o que fragilizam o trabalho nessa área.

Quando a educação das relações étnico-raciais é analisada a partir do ensino da Geografia escolar, constata-se que as orientações metodológicas e práticas de ensino nessa área do conhecimento apresentam lacunas de conteúdos e/ou desenvolvimento de práticas pedagógicas pontuais no contexto das unidades escolares. Existe uma distância enorme entre a Secretaria Estadual de Educação e o cotidiano escolar, especialmente quando esse cotidiano envolve o componente curricular Geografia.

As discussões que tratam da educação das relações étnico-raciais são fundamentais para o reconhecimento e valorização da cultura negra e indígena que, historicamente, foram 
marginalizadas e/ou silenciadas em nosso país, além de contribuir na luta contra as desigualdades sociais, raciais, étnicas e econômicas ainda existentes em nossa sociedade. Nesse contexto, é necessário que a Geografia escolar faça parte dessa discussão e contribua para a construção de uma educação antirracista.

A educação passa a adquirir, cada vez mais, um caráter multicultural. Consequentemente, começa também a ser pensada em razão de uma realidade que, agora em contato com a diversidade, toma dimensões nunca antes experimentadas. Nesse contexto, grupos historicamente marginalizados e invisibilizados passam a reivindicar suas pautas, ainda com mais veemência, pleiteando a necessidade de um sistema educacional que contemple a diversidade étnico-racial presente nas unidades escolares espalhadas por todo o país. Esses grupos agora ocupam os espaços que antes lhes eram negados, desta vez com seus conhecimentos, suas demandas políticas, crenças, valores, condições de vida, sofrimentos, desafios e conquistas. Passam a questionar os currículos colonizados, e ao mesmo tempo, colonizadores, exigindo novas propostas emancipatórias e uma nova perspectiva social, pautada na construção uma sociedade mais democrática e livre de preconceitos, superando assim, a equivocada crença de que vivemos uma democracia racial e lançando um novo olhar sobre formação do Brasil.

A implementação efetiva da Lei 11.645/2008 nos currículos escolares encontra resistências nas diversas esferas do sistema educacional do nosso país e, consequentemente, do Estado de Pernambuco. Nesse sentido, é fundamental que a sociedade se mobilize e cobre medidas que contribuam para que essa Lei se concretize de forma efetiva nos diversos níveis de ensino da educação. Precisamos, urgentemente, compreender que a inserção da temática história e cultura afro-brasileira e indígena no currículo escolar é mais que uma norma jurídica, é uma política pública de educação que pretende contribuir na formação de um ser humano que reconheça e valorize a pluralidade cultural, étnica e racial do povo brasileiro.

\section{AGRADECIMENTOS}

Pesquisa realizada com apoio do IFPE. 


\section{REFERÊNCIAS}

BARDIN, L. Análise de conteúdo. Tradução: Luís Antero Reto e Augusto de France. 4. ed. Lisboa: Edições 70, 2011.

BRASIL. Ministério da Educação/Secretaria de Educação Continuada, Alfabetização e Diversidade. Diretrizes Curriculares Nacionais para a Educação das Relações ÉtnicoRaciais e para o Ensino de História e Cultura Afro-Brasileira e Africana. Brasília, out. 2004.

CAVALCANTI, L. de S. Geografia, escola e construção de conhecimentos. 18. ed. CAMPINAS, SP: Papirus, 2013.

DENZIN, N. K.; LINCOLN, I. S. (Orgs.). O planejamento da pesquisa qualitativa: teorias e abordagens. 2. ed. Porto Alegre: Artmed, 2006.

DOMINGUES, P. Movimento Negro Brasileiro: alguns apontamentos históricos. Tempo, n. 23, p. 100-122, 2007. Disponível em: https://www.scielo.br/pdf/tem/v12n23/v12n23a07. Acesso em: 14 abr. 2020.

GOMES, N. L. Relações étnico-raciais, educação e descolonização dos currículos. Currículo sem fronteiras, v. 12, n. 1, p. 98-109, jan./abr. 2012. Disponível em: https://www.curriculosemfronteiras.org/vol12iss1articles/gomes.pdf. Acesso em: 29 abr. 2020.

MOTA, E. A. O negro e a cultura afro-brasileira: uma bricolagem multicultural do ensino de geografia. 222 f. Tese (Doutorado em Educação) - UFRJ, Rio de Janeiro, 2013. Disponível em: https://ppge.educacao.ufrj.br/tedmilsonmota.pdf. Acesso em: 12 mar. 2020.

OLIVA, A. R. A história africana nos cursos de formação de professores: panorama, perspectivas e experiências. Estudos Afro-Asiáticos, v. 28, n. 1-3, p. 187-219, jan./dez. 2006. Disponível em: http://repositorio.unb.br/handle/10482/6224. Acesso em: 17 jan. 2020.

PERNAMBUCO. Decreto $n^{\circ}$ 48.477, de 26 de dezembro de 2019. Institui o Regimento Escolar Unificado Substitutivo das Unidades Escolares da Rede Estadual de Ensino do Estado de Pernambuco. Recife: Alepe Legis, 2019. Disponível em: https://legis.alepe.pe.gov.br/texto.aspx?id=48557\&tipo=TEXTOORIGINAL. Acesso em: 5 jan. 2021.

PERNAMBUCO. Instrução Normativa n ${ }^{\circ}$ 04/2011. Orienta procedimentos quanto à inclusão no Currículo Oficial das escolas integrantes do Sistema Estadual de Ensino da obrigatoriedade 
da temática "História e Cultura Afro-Brasileira e Indígena". Diário Oficial do Estado de Pernambuco: Poder Executivo: Recife, Ano LXXXVIII, n. 28, p. 13, 9 fev. 2011. Disponível em: http://200.238.101.22/docreader/docreader.aspx?bib=2011\&pasta=FevereirolDia\%2009. Acesso em: 13 jul. 2020.

PERNAMBUCO. Lei no 15.533, de 23 de junho de 2015. Aprova o Plano Estadual de Educação - PEE. Recife: Alepe Legis, 2015. Disponível em:

https://legis.alepe.pe.gov.br/texto.aspx?tiponorma $=1 \&$ numero $=15533 \&$ complemento $=0 \&$ ano $=2015 \&$ tipo=\&url=. Acesso em: 20 ago. 2020.

PERNAMBUCO. Secretaria de Educação e Esporte. In: SECRETARIA DE EDUCAÇÃO E ESPORTE: educação: educação inclusiva. Recife: SEE, 2021. Disponível em:

http://www.educacao.pe.gov.br/portal/?pag=1\&men=179. Acesso em: 5 jan. 2021.

PERNAMBUCO. Secretaria de Educação e Esporte. Parâmetros para a Educação Básica do Estado de Pernambuco: Parâmetros Curriculares de Geografia - Ensino Fundamental e Médio. Recife: SEE, 2013. Disponível em:

http://www.educacao.pe.gov.br/portal/upload/galeria/4171/geografia_parametros_efm2013.pd f. Acesso em: 12 nov. 2020.

PERNAMBUCO. Secretaria de Educação e Esporte. Reorganização Curricular - Ensino Médio: expectativas de aprendizagem prioritárias e complementares de Geografia para os estudantes do Ensino Médio. Recife: SEE, 2020. Disponível em:

http://www.educacao.pe.gov.br/portal/?pag=1\&cat=18\&art=5649. Acesso em: 10 dez. 2020.

QUIJANO, A. “O que é essa tal de raça?”. In: SANTOS, Renato Emerson dos (org.). Diversidade, espaço e relações étnico-raciais: o negro no ensino de Geografia. Belo Horizonte: Autêntica, 2007.

SANTOS, R. E. dos. Ensino de Geografia e currículo: questões a partir da Lei 10.639. Terra Livre, São Paulo, v. 1, n. 34, p. 141-160, jan./jun 2010. Disponível em: http://www.agb.org.br/publicacoes/index.php/terralivre/article/view/315/298. Acesso em: 17 jan. 2020.

SANTOS, R. E. dos. O ensino de Geografia do Brasil e as relações raciais: reflexões a partir da Lei 10.639. In: SANTOS, R. E. dos (org.). Diversidade, espaço e relações étnico-raciais: o negro no ensino de Geografia. Belo Horizonte: Autêntica, 2007.

SECRETARIA ESTADUAL DE EDUCAÇÃO (PERNAMBUCO). Gerência Regional de Educação Metropolitana Norte. Plano de ação regional para a educação das relações 
étnico-raciais e para o ensino de história e cultura afro-brasileira e africana. Recife: SEE, 2016.

SILVA, A. C. O. da. Diversidades etnicorraciais e a política educacional em Pernambuco: a inclusão da História e Cultura Afro-Brasileira e Indígena como conteúdo curricular. 165 f. Dissertação (Mestrado em Educação) - UFPE, Recife, 2012. Disponível em: https://repositorio.ufpe.br/handle/123456789/12827. Acesso em: 26 set. 2020.

SILVA, M. da P. da. Educação intercultural: a presença indígena nas escolas da cidade e a Lei 11.645/2008. In: SILVA, E.; SILVA, M. da P. da. A temática indígena na sala de aula: Reflexões para o ensino a partir da Lei 11.645/2008. Recife: Ed. dos Organizadores, 2016.

VIEIRA, J. L. da; ROSA, W. T. Uma análise da temática história e cultura indígena no ensino de geografia: reflexões a partir da Região Metropolitana do Recife. Estudos Geográficos, Rio Claro, v. 17, n. 1, p. 217-233, jan./jun. 20219. Disponível em:

https://www.periodicos.rc.biblioteca.unesp.br/index.php/estgeo/article/view/14084. Acesso em: 20 jan. 2021.

WITTMAN, L. T. Introdução ou escrita da história indígena. In: WITTMAN, L. T. (org.). Ensino (d)e história indígena. Belo Horizonte: Autêntica, 2015. 